\title{
Rethinking College Student Development Theory Using Critical Frameworks
}

Edited by: Elisa S. Abes, Susan R. Jones, and D-L Stewart

Published by: Sterling, VA: Stylus Publishing, 2019, 286 pages

Reviewed by: Valerie Luutran, Coordinator, Orientation, Transition and Parent Programs, University at Buffalo

Within orientation, transition, and retention (OTR) and the broader scope of the student affairs profession, we collectively value practice informed by theory and research. However, despite it being nearly 100 years since our seminal text, The Student Personnel Point of View (American Council on Education, 1937), was published, we rarely take time to revisit and critique the theories informing our work. In Rethinking College Student Development Theory Using Critical Frameworks, Elisa S. Abes, Susan R. Jones, and D-L Stewart do just that by directing the work toward practitioners and avoiding the frequently inaccessible academic jargon associated with theory.

While not focused explicitly on new student programming, I would strongly recommend this book to OTR professionals dedicated to more equitable and just practices (so hopefully all of us!) and who work directly with students or shape programs, policies, or structures at the campus level. Regardless of how consciously student affairs professionals integrate theory into their daily work, they will find value in the many practical applications offered in this book and be pleasantly surprised by the commonsense (rather than overly scholarly) approach taken. The text steps away from performative discussions of theory and best practice. Instead, contributors like Susan B. Marine ask, "Do we just know goodness within the student affairs profession when we see it, and when we do, does it look like justice?" (p. 207). Though coming late in the book, this sentiment is a guiding premise for the treatment of theory and practice across all chapters.

In Part 1, contributors present six frameworks comprising the third 
wave of student development theory: (a) critical race theory (CRT), (b) intersectionality, (c) critical feminist theories (FemCrit), (d) decolonizing/Indigenous theories, (e) queer theory, and (f) crip theory. Susan R. Jones suggests these third-wave theories share an emphasis on "emancipation and societal transformation [,] ... attention to larger structures of inequality, and the necessity of meaningfully integrating theory and practice ... to promote social change" (p. 11). Unfortunately, these frameworks are also likely missing from the curriculum of many student affairs graduate programs. As a recent graduate of a master's program, I was familiar with CRT, but I was humbled by how little I knew of the other paradigms discussed here.

In each chapter, the authors describe the central tenets of a framework and share examples of application to student development programs and services. The practice discussions helped me understand later chapters where the frameworks are deployed to deconstruct and reconstruct seminal concepts from student development theory. I appreciated the opportunity to reconnect with and expand my knowledge of various theories, recognizing that as practitioners, we can often forget to hold space for ongoing learning once we leave graduate programs and enter professional roles.

The latter part of each chapter includes clear recommendations for practice, suggestions for further reading, and questions for discussion. The structure of these brief chapters moves readers quickly to a detailed discussion of application in Part 2 while putting the onus on the reader to further educate themselves and grow as informed, socially just practitioners. These features make me eager to recommend the book to all my colleagues.

In Part 2, contributors use the critical and poststructural frameworks introduced in earlier chapters to examine seven core theoretical constructs: (a) resilience, (b) dissonance, (c) socially constructed identities, (d) authenticity, (e) agency, (f) knowledge and knowing, and (g) context. The editors intentionally organized this section by construct rather than specific theory or social group to encourage readers to think more broadly and boldly about student development as holistic and integrated.

Each chapter provides a compelling analysis, beginning with a personal narrative that centers the construct within a college student's experience 
(typically one of the authors) and followed by a rethinking of that construct. The authors use these personal narratives to guide readers through reflective observation into abstract conceptualization of how a critical reexamination could have better equipped the student to succeed or allowed a practitioner to avoid unnecessary harm.

In Chapter 9, Kari B. Taylor and Danyelle J. Reynolds showcase an experience that crossed "the line between creating dissonance and inflicting trauma during an educational experience" (p. 104). Reynolds described an international service-learning trip she took in college. During training, the site liaison emphasized considering colonial history when interacting with the community, and Reynolds expected to find commonality with the local Ecuadorians due to shared experiences navigating colonialism and structural racism. Instead, she experienced dissonance once she entered the community and encountered clear resistance from schoolchildren. She later learned the site liaison was aware of the rampant anti-Black racism in the community but had not wanted to share this ugly truth with the volunteers.

The authors discuss this narrative through a Black feminist theoretical lens and demonstrate how dissonance is inseparable from societal power dynamics. This reframing is valuable for OTR professionals, particularly as we develop diversity and inclusion training for student leaders or even new students. Thus, we can recognize dissonance as a valuable learning tool that may also pose an inherent risk to those who hold oppressed identities. For example, privilege walks are a common strategy for "exposing" students from majority groups to systemic injustices their minoritized peers face every day. Yet, they function to the detriment, embarrassment, and trauma of those peers whose lived experiences are displayed as teachable moments for others. Instead of automatically adopting such practices, we should consider how we can leverage affinity spaces and discussion to name lived realities, promote cultural exchange, and challenge our students without risking harm.

Part 3 is a call to critically examine three concepts widely celebrated in student affairs practice-student involvement and engagement, principles of good practice, and high-impact practices-and integrate the reconstructed concepts into our personal and professional worldviews to engage in truly liberatory practice. The authors skillfully challenge these taken-for-granted "goods," sharing personal experiences and encouraging reflection. 
The discussion around involvement and engagement raised insights particularly relevant to OTR work. In Chapter 15, Daniel Tillapaugh recounts telling students and families at orientation, "research tells us that students who [get involved in college] perform better, are more satisfied with their college experience, and [graduate] at higher rates" (p. 191). I would be shocked if near-identical messages didn't appear in most OTR programs. The chapter forced readers to reflect on why encouraging involvement as the avenue to success can be a narrow and even harmful message, particularly for minoritized students who do not find their campus a space where they feel safe to engage.

Tillapaugh challenges the idea there is a home for every student on campus. How much of a false reality do we promote when we tell students to "find their niche" on a campus not built for them or when the various niches available (e.g., student organizations) tend to focus only on single identities rather than students' multiple social identities? As we talk about the college experience with new students and their families, insights from this chapter are helpful to broaden our view of involvement to include jobs and off-campus, community, or home involvement that provides different levels of support.

The editors conclude the volume with personal narratives and, as in earlier chapters, a set of discussion questions. The personal stories and guided reflection are what I found to be the most impactful and unique about Rethinking College Student Development Theory. While built on complex theoretical frameworks, the text is undoubtedly a practitioner's guide. In addition, the book's format makes it easy to use select chapters for targeted readings and discussions. Finally, facilitators' jobs are made easier with the reflective discussion questions provided in each chapter.

Overall, I would recommend this text (as a whole or select chapters) as a shared office or divisional read. I found myself having "aha!" moments with each page turn and jotting down notes and recommendations specifically for my programs. I felt empowered and saw avenues for change within my sphere of influence. Rethinking College Student Development Theory is a game-changer for the OTR field as it will help professionals think more critically about how to better align programs, policies, and personal actions with a movement for justice and liberation.

Late in the book, the editors write, "[c]ritical (re)constructions of student development are not just fodder for heady debates and banter among 
scholars" (p. 189). The real contribution of this book is that it encourages reflection around student development without getting bogged down by academic jargon that can make these conversations inaccessible, elitist, and therefore unappealing to many practitioners.

\section{References}

American Council on Education, Committee on Problems and Plans in Education. (1937). The student personnel point of view. 